\title{
La Participación Empresarial en la Conspiración Golpista en Argentina (1975-1976)
}

\author{
Gonzalo Sanz Cerbino
}

Universidad de Buenos Aires (UBA). Buenos Aires, Argentina. E-mail: camilogx@yahoo.com

\section{INTRODUCCIÓN}

E 1 debate en torno al golpe de Estado que se produjo en Argentina el 24 de marzo de 1976 ha sido un tópico bastante explorado en las Ciencias Sociales en el Cono Sur. La violenta represión que se desencadenó tras el acceso de las Fuerzas Armadas al poder, con su secuela de torturas, centros clandestinos de detención, presos políticos y "desaparecidos", ha dado pie a una gran cantidad de trabajos sobre el tema (Águila, 2008). Sin embargo, algunas aristas de este suceso solo recientemente han comenzado a ser objeto de estudios académicos. Es el caso, por ejemplo, de la complicidad de ciertos sectores del empresariado que promovieron el golpe y la represión. Esta no había sido una preocupación para los cientistas sociales en los años 1980, cuando empezaron a aflorar los trabajos sobre el golpe de 1976. Seguramente influyó sobre este sesgo la línea de interpretación dominante en la época, la llamada "teoría de los dos demonios". Ésta planteaba que el golpe y la represión habían sido producto de una "espiral de violencia" protagonizada por dos actores, la "ultraizquierda" y la "ultraderecha", mientras que el grueso de la sociedad habría permanecido ajena a los sucesos (Vezzetti, 2002; Izaguirre, 1998). Este paradigma, fuertemente reduccionista, no solo simplificaba el complejo proceso que llevó a la agudización de los enfrentamientos sociales en los años previos a 1976,

DADOS - Revista de Ciências Sociais, Rio de Janeiro, vol. 59, no-1, 2016, pp. 171 a 202. 
sino que libraba también de culpa a aquellos sectores que se movilizaron a favor del golpe y respaldaron la acción militar.

Sin embargo, poco a poco este problema ha empezado a plantearse en los trabajos realizados desde las Ciencias Sociales. Quienes han profundizado sobre la política económica de la dictadura y las transformaciones producidas en el entramado industrial se ocuparon de señalar qué sectores del empresariado se beneficiaron con estos procesos (Schvarzer, 1987; Aspiazu, Basualdo y Khavisse, 2003; Castellani, 2010). Otros trabajos han reconstruido los posicionamientos de corporaciones empresariales en los meses previos y posteriores al golpe, resaltando el apoyo de estas entidades a la dictadura (Palomino, 1988 y 1989; Schvarzer, 1990). No obstante, se trata, en ambos casos, de trabajos parciales que no han terminado de identificar el conjunto de los sectores del empresariado que impulsaron o respaldaron el golpe. Resolver este problema demandaría avanzar en una reconstrucción de la ofensiva golpista que comenzó en 1975, de la que participó buena parte de las corporaciones representativas de la burguesía. Algunos autores han intentado realizar este ejercicio, pero el abordaje parcial, centrado solo en algunas de las fracciones del empresariado que promovieron el golpe, no termina de arrojar luz sobre el asunto de manera más global (Sidicaro, 2002; Rapoport y Zaiat, 2013).

Es precisamente este el horizonte y el objetivo principal del presente artículo. Apoyados en un extenso relevamiento documental, intentaremos reconstruir el accionar de la burguesía durante el año 1975 y los primeros meses de 1976. Nos centraremos en la crisis del Gobierno peronista y en la constitución de una alianza social decidida a impulsar la toma del poder por parte de las Fuerzas Armadas, a la que se sumaron importantes sectores de la burguesía. Analizaremos las posiciones políticas y el accionar de diferentes agrupamientos empresariales, las relaciones trazadas con los militares golpistas y la tendencia a confluir con ellos. Tras ese recorrido, esperamos reconstruir algunos de los aspectos menos conocidos del golpe de Estado instaurado en la Argentina en marzo de 1976.

\section{EL PERONISMO, LA BURGUESÍA ARGENTINA Y LA CRISIS}

El golpe de 1976 constituyó un nuevo intento de cerrar una crisis que la Argentina arrastraba desde mediados de los años 1950. En términos políticos, la primera manifestación de la crisis fue el golpe de Estado 
que, en 1955, derrocó a Juan Domingo Perón. Tras el golpe, ninguna fuerza política logró consolidarse en el poder. Durante veinte años se alternaron administraciones civiles y militares, desplazadas sucesivamente del Gobierno. Ningún presidente surgido del voto logró culminar su mandato, tanto por el acoso permanente de las Fuerzas Armadas como por la ilegitimidad derivada de elecciones fraudulentas. Es que el peronismo, la fuerza política mayoritaria, fue proscripta y su líder terminó confinado al exilio. Los regímenes militares no tuvieron mejor suerte, y se vieron sacudidos por crisis internas y estallidos sociales que obligaron a abortar planes y dar paso, nuevamente, al régimen democrático que su intervención había cancelado. El trasfondo de esta crisis de dominación política era una profunda división en la clase dominante. Como ha señalado O’Donnell, la vertiginosa alternancia de regímenes políticos y Gobiernos era el resultado de la sucesión en el control de los resortes del Estado de dos alianzas, dirigidas por distintas fracciones de la burguesía, con diferentes propuestas programáticas para restaurar la dominación (O'Donnell, 2008 y 2009). Estos programas postulaban soluciones contrapuestas a la crisis económica cíclica que trababa la acumulación de capital y socavaba las bases del poder social. En última instancia, en esa crisis económica irresuelta se encuentra la explicación última de la crisis política y la agudización de los enfrentamientos sociales.

A comienzos de la década de 1950, el país entró en un ciclo errático en el que fases de crecimiento económico fueron sucedidas por estruendosas caídas. Entre fase y fase, aparecía el fenómeno de la crisis de la balanza de pagos, por el desajuste entre los ingresos por exportaciones e importaciones, y la crisis fiscal. Este fenómeno obligaba a implementar devaluaciones y ajustes, en un intento por descargar la crisis sobre el sector obrero, que vio sus salarios reales cercenados por la inflación mientras se cancelaba cualquier tipo de negociación paritaria. Los vaivenes económicos se reflejaron en la evolución errática de la tasa de ganancia agraria e industrial en el período, de la productividad del trabajo y del PBI (Iñigo Carrera, 2007). La renta agraria, que operó en algún momento como factor de compensación y permitió el desarrollo de las fuerzas productivas en la Argentina, comenzó a agotarse a partir de la década de 1950.

Hasta ese momento, la renta diferencial de la tierra permitió un crecimiento industrial considerable, pero incapaz de sostenerse sin transferencias de ingresos del agro, por carecer de competitividad internacio- 
nal. Dichas transferencias comenzaron a mostrar su incapacidad para seguir sosteniendo el esquema en este periodo. El capitalismo argentino se enfrentaba así a una profunda crisis de acumulación. La renta ya no alcanzaba para todos, lo que ponía sobre la mesa la necesidad de realizar un ajuste. Los candidatos a pagar los costos de la crisis eran, por un lado, la clase obrera, que veía amenazado el nivel de vida conquistado durante las décadas previas. Y, por otro, las capas más débiles de la burguesía, que necesitaban, para sostenerse, de las transferencias de ingresos bajo distintas formas (subsidios, protección del mercado interno, crédito barato).

La necesidad del ajuste puso a la orden del día el enfrentamiento interburgués. En líneas generales, asistimos al combate entre dos programas que se proponían como solución a la crisis, el "liberal" y el "reformista", que tuvieron carnadura en dos fuerzas sociales o alianzas. Los primeros postulaban la realización de un profundo ajuste, eliminando las transferencias de renta hacia la industria protegida y avanzando sobre las conquistas sociales que la clase obrera había obtenido bajo el peronismo.

De esta manera, se liberarían las tendencias a la concentración y centralización de capital, relanzando la acumulación, pero con altos costos sociales. La alternativa reformista expresaba la resistencia a este programa de las fracciones más débiles de la burguesía en alianza con la clase obrera. Ambas alianzas se alternaron en el poder entre 1955 y 1973, sin dar una salida a la crisis. La implementación del programa liberal terminó abortándose en medio de conflictos sociales generados por sus mismas políticas económicas. Por otra parte, el programa reformista sucumbió por la constante reedición del cuello de botella económico al que no podía dar solución (O’Donnell, 2008:19-64).

La incapacidad de la clase dominante para ofrecer una salida a la crisis derivó en un deterioro de las condiciones de vida para la clase obrera y la pequeña burguesía. Ambos sectores sufrían un doble embate desde las altas esferas: los ataques en el terreno económico (congelamiento salarial, desocupación, despidos en empresas estatales, proletarización de los profesionales, desaparición del pequeño comercio) y político (proscripción del peronismo, represión, ilegalización de la actividad sindical, intervención de las universidades). En esta situación, los lazos ideológicos y políticos que sustentaban la dominación comenzaron a debilitarse. Desde comienzos de los años 1960, empezaron a aflo- 
rar síntomas de una crisis hegemónica que se estaba incubando: crecientes enfrentamientos sociales, surgimiento de organizaciones de izquierda que intentaban desarrollar la lucha armada, "peronización" de las clases medias, radicalización de los intelectuales y movilización de los estudiantes.

El año 1969 emerge en medio de la crisis como un divisor de aguas. En mayo de ese año, estalló una huelga general de masas en la provincia de Córdoba, con características insurreccionales. Confluyeron en ella, con distintas demandas, estudiantes universitarios y sectores del movimiento obrero, que arrastraron a la protesta callejera a buena parte de la población de la zona. Los sectores movilizados tomaron el control del territorio, levantando barricadas y enfrentando a las fuerzas represivas locales que, desbordadas, se vieron obligadas a retroceder. Solo la intervención del Ejército Nacional logró contener, momentáneamente, la situación. La tendencia de las masas a la acción directa y su disposición a enfrentarse con el régimen en las calles revelaban un cambio en el clima político nacional. Estas tendencias, a su vez, no se agotaron en el "Cordobazo", como se lo llamó, sino que siguieron desarrollándose. En septiembre de 1969, una nueva insurrección estalló en Rosario, y al año siguiente los levantamientos provinciales sumarían cinco. Entre 1969 y 1973, se produjeron 17 insurrecciones locales (Izaguirre et al., 2009; Balvé y Balvé, 2005). En ellas, iba creciendo la influencia y el rol dirigente de partidos y agrupamientos que planteaban una transformación revolucionaria de la sociedad. Ese crecimiento de las tendencias de izquierda también se manifestaba en el movimiento obrero, en donde el "clasismo" comenzaba a rivalizar con la dirección tradicional peronista (la "burocracia sindical").

Otra manifestación del mismo proceso fue el crecimiento de las organizaciones político-militares de izquierda, y de las acciones armadas que emprendían con importante despliegue de capacidad operativa. Este movimiento ponía en evidencia la constitución, aún incipiente, de una nueva alianza que comenzaba a terciar en la disputa política. Aunque el programa y la estrategia eran todavía difusos, y se debatían entre el socialismo revolucionario y variantes radicalizadas del peronismo, lo que quedaba claro era la irrupción de sectores de la pequeña burguesía y de la clase obrera que comenzaban a intervenir en el proceso político con independencia de las dos alternativas de poder encabezadas por la burguesía. 
Las tendencias insurreccionales abiertas con el Cordobazo incidieron en el proceso político y generaron una crisis de régimen en el Gobierno dictatorial. En poco menos de dos años, dos presidentes militares y varios ministros debieron renunciar. Sin embargo, los cambios no alcanzaron para contener la creciente insubordinación popular, lo que obligó a giros más drásticos. Una fracción del Ejército, en 1971, se alzó con el poder para ofrecer una salida política: una apertura electoral sin restricciones, o sea, que permitiera la participación del peronismo. La apertura democrática y el retorno del peronismo no eran un resultado casual, sino una estrategia consciente de ciertos sectores de la burguesía para contener y reencauzar en los marcos del sistema un descontento popular que comenzaba a desbordarlo.

Tanto las Fuerzas Armadas como los partidos políticos, que habían avalado hasta ese momento la proscripción del peronismo, se posicionaron por la apertura democrática irrestricta (O'Donnell, 2009:319-434). También lo hicieron importantes entidades empresariales, muchas de ellas abiertamente "antiperonistas" hasta poco antes ${ }^{1}$. De esa forma, planteándose como objetivo contener la movilización popular y conjurar la crisis económica, el peronismo logró retornar al poder en las elecciones realizadas a mediados de 1973. Sin embargo, la experiencia no duró más de tres años.

El retorno de Perón permitió canalizar el descontento de las masas por la vía institucional. El apoyo al nuevo Gobierno fue mayoritario, incluso en sectores que hasta poco antes habían enarbolado la lucha armada. Desde la Confederación General del Trabajo (CGT), dominada por la derecha peronista, hasta los agrupamientos de la izquierda peronista o filoperonista (Montoneros y las Fuerzas Armadas Revolucionarias, entre otros) se sumaron al "Gobierno popular". En el campo de la clase dominante, vencidas las primeras resistencias, el peronismo consiguió un apoyo nada desdeñable. La Confederación General Económica (CGE), que aglutinaba a los pequeños y medianos empresarios, impulsó tempranamente el retorno del peronismo y diseñó el plan económico que esta fuerza pondría en marcha en 1973. La Unión Industrial Argentina (UIA), tradicionalmente enfrentada a los empresarios reformistas, dio un giro en sus posiciones hacia 1972, y se acercó a los postulados que impulsarían el nuevo Gobierno. En 1973 declaró su apoyo abierto a las nuevas autoridades y terminó fusionándose con la CGE. Las corporaciones agrarias, afectadas por una política económica que elevaba las transferencias de renta hacia la industria urbana y 
los asalariados, se dividieron ante el nuevo escenario. Los pequeños productores agropecuarios, representados por la Federación Agraria Argentina (FAA) y la Confederación Intercooperativa Agropecuaria (Coninagro), respaldaron inicialmente al Gobierno y ocuparon cargos en la función pública. Esperaban beneficiarse tanto de las políticas de segmentación de carga impositiva como de aquellas que apuntaban a reformar la estructura de tenencia de la tierra. Por el contrario, los productores de mayor tamaño, representados por la Sociedad Rural Argentina (SRA), las Confederaciones Rurales Argentinas (CRA) y la Confederación de Asociaciones Rurales de Buenos Aires y La Pampa (Carbap), resistieron el retorno del reformismo que avanzaría sobre sus ingresos, no sin sufrir divisiones internas. Sin embargo, hacia 1973, sin mucho margen de acción tras el abrumador triunfo electoral del peronismo, morigeraron su crítica y hasta respaldaron en actos públicos la política oficial ${ }^{2}$.

La amplia red de apoyos que supo granjearse Perón en su regreso al país puede ser explicada tanto por su programa económico como por ciertas variables de la coyuntura política. En términos económicos, el peronismo impulsó un plan de cuño claramente reformista, elaborado por la CGE. José Ber Gelbard, histórico dirigente de la entidad, asumió como ministro de Economía. El programa apuntaba a concretar una reactivación del mercado interno, contener la inflación y proteger el entramado industrial mercado-internista. La crisis intentó ser resuelta, nuevamente, por medio de ingresos del agro a la industria. Este programa, inviable durante el período previo en el que los bajos niveles de renta obligaron a realizar ajustes a nivel salarial, de gastos estatales y transferencias a la industria, era ahora posible merced a una coyuntura internacional claramente favorable. Los altos niveles de renta agraria, por la elevación extraordinaria de los precios internacionales de los principales productos de exportación, hicieron que este programa tuviera, por lo menos en el corto plazo, posibilidades de realización (Iñigo Carrera, 2007:41-45).

Una vez más, se colocaba al agro en un lugar central, como el sector que financiaría el plan. A través de la estatización del comercio de granos y carnes (con la subsiguiente fijación estatal de los precios internos), las retenciones y, sobre todo, de una sobrevaluación cambiaria que alcanzó, entre 1974 y 1975, un 45\%, los sectores no terratenientes se apropiaron del grueso de la renta diferencial. Los subsidios y el crédito promocional fueron las vías principales en que la renta captada por el Estado 
fue a parar al ineficiente entramado industrial (Castellani, 2010:85-94). Pero la iniciativa más importante encarada por Gelbard fue el acuerdo entre una fracción del empresariado y las cúpulas sindicales, destinado a contener la inflación. El acuerdo, denominado "Pacto Social", fue suscripto por la CGT y la CGE, aprobado por el conjunto de la burguesía industrial, y aceptado (a regañadientes en más de un caso) por casi todas las capas de la burguesía agraria, que podían soportar una mayor carga tributaria por la coyuntura de altos ingresos.

A partir de la firma del "Pacto Social", los empresarios se comprometieron a no aumentar los precios o realizar sustanciales rebajas en algunos renglones de la producción, y los dirigentes sindicales a no encarar luchas por aumentos de sueldo. El acuerdo tenía implicaciones que trascendían los objetivos económicos: el cerrojo que se imponía sobre los conflictos salariales apuntaba no solo a contener la inflación, sino a aquietar las aguas de la conflictividad obrera. El intento de contener las luchas sociales fue uno de los pilares de la política del nuevo Gobierno: para ello, no solo se apeló a la concesión de ciertos reclamos económicos y sociales, como los que parcialmente contemplaba el Pacto Social, sino también al endurecimiento de la política represiva. Además de los instrumentos legales promovidos con ese fin, Perón apeló también a la violencia paramilitar, avalando los crímenes de organizaciones de extrema derecha ideadas por funcionarios de su propio Gobierno, como la "Triple A" (Izaguirre et al., 2009:143-235).

Las excelentes condiciones económicas externas que hicieron viable el Pacto Social durante 1973 y la primera mitad de 1974 permitieron sostener las alianzas trazadas por el Gobierno peronista. En el campo de la clase dominante, la oposición fue neutralizada y quedó reducida a pequeños núcleos de la burguesía rural. Sin embargo, el armado comenzó a tambalear en la segunda mitad de 1974. La crisis económica internacional comenzó a golpear las puertas de la Argentina. El primer revés lo produjo el violento aumento de los precios del petróleo, que encareció las importaciones. La recesión internacional también redujo los ingresos por exportaciones: los socios comerciales de la Argentina comenzaron a imponer restricciones al ingreso de productos locales y a reducir la demanda, arrastrando los precios hacia abajo. Uno de los primeros síntomas de la reversión de las condiciones externas favorables fue el cierre de las exportaciones de carnes argentinas al Mercado Común Europeo, en julio de 1974. 
De esta manera, se deterioraron los términos de intercambio, se redujo significativamente el superávit comercial y las reservas, y comenzó a vislumbrarse nuevamente una crisis de balanza de pagos. El aumento de precios en los bienes importados también impactó sobre los costos internos, en un contexto de inflación contenida, a punto de estallar. Desde los comienzos de 1974, obreros y empresarios presionaron a Gelbard para obtener aumentos vedados por el Pacto Social. A su vez, se había generalizado un mecanismo al que la burguesía recurrió para violentar el acuerdo de precios: los bienes eran retirados de la circulación, generando desabastecimiento, para luego ofrecerlos a valores más altos en el mercado negro. Las perspectivas externas e internas, por otro lado, dificultaban continuar con una política monetaria expansiva y obligaban a contener los gastos estatales (Rapoport, 2000:690-702; Kandel y Monteverde, 1976).

El Pacto Social empezaba a hacer agua, y la situación política tras la muerte de Perón, a mediados de 1974, terminaría de enterrarlo. El ministro de Economía perdió uno de sus últimos respaldos con la muerte de Perón, en un contexto en que la crisis avanzaba. La caída de los precios ganaderos permitió a los sectores opositores al reformismo en el agro ganar posiciones dentro de las corporaciones. Estos sectores, entre los que comenzaba a destacarse la figura del ganadero Jorge Aguado, ganaron la dirección de las CRA y acrecentaron su influencia sobre la SRA y Coninagro. A su vez, dentro de la FAA, creció la oposición a la dirección reformista de la entidad. Además de la crítica al avance gubernamental sobre los ingresos del sector, se destacó la oposición a un intento oficial de reformar la estructura de tenencia de la tierra ${ }^{3}$.

La ofensiva de la burguesía agropecuaria sobre la gestión del ministro Gelbard fue acompañada por un sector interno del Gobierno, comandado por el ministro de Bienestar Social López Rega, líder del ala derecha y creador de la Triple A. Acosado y sin respuestas a la crisis, Gelbard terminó renunciando en octubre de 1974 y fue reemplazado por Gómez Morales, que intentó contener la situación por medio de un ajuste moderado sobre las variables económicas. El nuevo ministro desandó el camino marcado por Gelbard, puso en marcha la "flexibilización" de los precios e impuso una política monetaria más restrictiva. El ajuste gradual que caracterizó su gestión no solo fue producto de su concepción económica, que prefería evitar restricciones más drásticas para escapar a la recesión, sino también de la necesidad de aplacar los 
conflictos sociales. El ajuste de tarifas que buscaba equilibrar las cuentas fiscales debió esperar hasta febrero de 1975, la devaluación para corregir el retraso cambiario se demoró hasta el final de su gestión, y los aumentos salariales siempre fueron mayores a los que el ministro creía necesarios. En materia de política agropecuaria, también se imprimió un giro importante, con el congelamiento de toda iniciativa de reforma de la estructura de tenencia de la tierra. Sin embargo, no se aflojó la presión fiscal sobre el agro. El esquema económico, asolado por la crisis internacional, no podía darse el lujo de ceder en los niveles de renta apropiados por el Estado.

De este modo, la "flexibilización" de los precios de las manufacturas no alcanzó en igual medida a los precios agropecuarios. El proceso inflacionario, que comenzaba a acentuarse con la política de Gómez Morales, imprimía, a su vez, mayor retraso con relación a los costos que se elevaban vertiginosamente. Así, el problema de los ingresos se impuso como el principal reclamo de las corporaciones agropecuarias al Gobierno durante 1975. El deterioro de los precios agropecuarios en relación con los costos generó una situación explosiva en el sector que se extendió a lo largo de 1975. El fenómeno obedecía, en primer lugar, al derrumbe de los precios internacionales. En dólares corrientes por tonelada, los precios de trigo habían caído un 27,3\% entre 1974 y 1976, el maíz, un $11,5 \%$, en el mismo período, y la carne, un 31,6\%. A su vez, en el mercado interno se conjugaban precios oficiales bajos, que se mantenían invariables ante el avance de la inflación. Entre enero y abril de 1975, el precio real del novillo había caído un $16 \%$ y el de trigo, un $19 \%$. Esto arrastró la tasa de ganancia agraria, que, de valores superiores al 20\% entre 1972 y 1974, se desplomó al 7,9\% en 1975, con lo que alcanzó el punto más bajo de la serie 1950-1980 (Ferreres, 2007; Iñigo Carrera, 2007:44-85).

Por estas razones las corporaciones rurales iniciaron un proceso de unificación y protestas. En diciembre de 1974, la SRA, las CRA y la Coninagro conformaron el Comité de Acción Agropecuario (CAA), que en marzo de 1975 se lanzaría a la acción directa. La FAA se mantuvo por unos meses al margen de la iniciativa unitaria, aunque fue una de las más activas en la protesta contra el Gobierno. Durante 1975 se impuso una modalidad de acción que reconocía pocos antecedentes en la historia argentina: los "paros agrarios". Dicha forma de protesta implicaba que los productores primarios no enviarían su producción a los mercados durante los días que durara la medida. Aunque esta protesta 
tenía un carácter demostrativo, podía generar desabastecimiento y aumentos de precio si se mantenía durante varios días. Fue acompañada a su vez por movilizaciones, cortes de ruta y actos de intimidación violentos para garantizar el acatamiento mayoritario. Entre enero y junio de 1976, se realizaron 11 paros agrarios de alcance regional y 3 de alcance nacional, lo que indicaba la existencia de una disposición al enfrentamiento nunca antes vista en la burguesía rural.

Los paros regionales desarrollados en distintas zonas del país tuvieron duraciones variables (entre 1 y 15 días), afectaron a distintos productos (lana, carne vacuna, granos, frutas y lácteos) y fueron impulsados por la FAA junto con pequeñas corporaciones regionales. A su vez, se realizaron tres paros de alcance nacional. El primero de ellos, el 3 de marzo, fue impulsado por el CAA con una duración de $24 \mathrm{~h}$. Tras ese paro, el CAA se vio envuelto en disputas intestinas, entre un sector comandado por Jorge Aguado, dirigente de las CRA y la Carbap, quien postulaba la necesidad de intensificar la protesta; y la dirigencia de la SRA y Coninagro, que buscaba evitar el enfrentamiento directo con el Gobierno. Por esa razón, el siguiente paro agrario nacional fue impulsado por las CRA y la FAA, que trazaron una alianza con el objetivo de magnificar la protesta de cara a la disolución del CAA. Este paro, que comenzó el 19 de mayo, involucró a la producción ganadera y tuvo una duración de tres días. Poco después, el 4 de junio, los mismos sectores impulsarían un paro de la producción láctea, también por tres días, al que se sumó la SRA ${ }^{4}$.

La primera mitad de 1975 transcurría en un clima enrarecido por el recrudecimiento de la crisis y la movilización de la burguesía agraria. El ministro de Economía, Gómez Morales, intentando evitar un estallido social, no avanzaba con el ajuste que demandaba la economía. Sin embargo, lentamente se iba avanzando en algunas medidas de ajuste que solo servían para fortalecer las posiciones de los partidos de izquierda dentro de las fábricas. El Gobierno se debatía en conflictos intestinos, y comenzaba a resquebrajarse el bloque de poder. La rebelión de la burguesía agraria, encabezada por sectores que habían apoyado al peronismo (como la FAA) era un síntoma de ello. En medio de la crisis, el Gobierno intentó un brusco golpe de timón al reemplazar a Gómez Morales por un nuevo ministro, Celestino Rodrigo, que implementó un violento ajuste de las variables económicas mediante un programa de shock. El fracaso de este intento selló la suerte del Gobierno peronista: a partir de ese momento, casi todas las fracciones de la 
burguesía avanzarían con una ofensiva que apuntaba claramente a consumar un golpe de Estado.

\section{DEL “RODRIGAZO" A LA OFENSIVA GOLPISTA DE LA BURGUESÍA}

El programa que Rodrigo intentó aplicar consistía en un brusco descenso de los salarios reales, que se constituiría en la base de un relanzamiento de la acumulación de capital por la vía de un gigantesco aumento de la explotación. En términos generales, el plan se basó en una importante devaluación de la moneda y un fuerte aumento de precios y tarifas, que no serían acompañados por reajustes salariales, a los que el Gobierno fijó un tope menor que al aumento de precios. Sin embargo, pronto el plan se encontró con un obstáculo político: la resistencia de la clase obrera a ser la variable de ajuste. Rápidamente comenzaron a estallar huelgas parciales y movilizaciones contra lo que se conoció como "Rodrigazo".

\section{El "Rodrigazo" y las Resistencias}

Dirigida por cuadros de la izquierda revolucionaria, la resistencia al plan comenzó a generar órganos de coordinación que rebasaron la conducción de la burocracia sindical peronista (Restivo y Dellatorre, 2005; Löbbe, 2009). El fracaso del programa, que expresaba los intereses de las fracciones más concentradas y poderosas de la burguesía, ofició como punto de inflexión y puso en evidencia que los marcos del régimen democrático no eran los más adecuados para imponer una política económica que implicaba un férreo avance sobre las conquistas laborales.

En términos estrictos, los únicos empresarios que se opusieron al plan de ajuste fueron algunos sectores de la CGE, el baluarte reformista. Entre las corporaciones agrarias, la Coninagro y SRA manifestaron su respaldo a la gestión económica y a las medidas impulsadas ${ }^{5}$. Las CRA y la FAA plantearon desconfianzas, pero no cuestionaron las medidas de ajuste sino que exigieron su profundización ${ }^{6}$. El sector industrial se mostró dividido frente al Rodrigazo. La división se procesó al interior de la CGE, que desde la fusión con la UIA aglutinaba al grueso de los industriales. Tras un mes sin pronunciarse sobre la nueva gestión económica, la dirección nacional de la CGE emitió un cuestionamiento al balance de la situación que hacía el ministro Rodrigo: lo acusaban de 
exagerar los alcances de la crisis para justificar la implementación de medidas impopulares.

Su balance, sin embargo, fue defendido por viejos dirigentes de la UIA integrados a la CGE. De esa forma, justificaron el ajuste implementado, que venía a reparar los "desaciertos" que achacaban a la gestión de Gelbard, el hombre fuerte de la CGE (Baudino, 2012:254-276). El Rodrigazo también fue defendido por el Consejo Empresario Argentino (CEA), que tendría un rol protagónico en la gestación del golpe de marzo de 1976. El CEA, formado en 1967, reunía a un puñado de empresarios (no más de 30) representantes de los capitales más concentrados de la Argentina. Lo integraban Techint y Acindar, dos de las metalúrgicas más importantes del país, Alpargatas, una de las más grandes fábricas de calzado y confección, automotrices como Fiat y Ford, las petroleras Astra y PASA, la química Duperial, la alimenticia Noel, grandes empresas comerciales como Bunge y Born o Sociedad Comercial del Plata, los bancos Alemán y Galicia, la papelera Celulosa, entre otras. Su influencia sobre el poder político, que se había opacado con el retorno del peronismo, se acrecentaría notablemente tras el golpe: su presidente, José Martínez de Hoz, sería el primer ministro de Economía de la dictadura (Restivo y Dellatorre, 2005: 17-49; Baudino, 2012: 174-183).

Los alineamientos en torno al programa de Celestino Rodrigo prefiguraban lo que sucedería tiempo después. La burguesía rural grande (SRA y CRA) y chica (FAA) y los capitales más concentrados de la industria, las finanzas y el comercio (CEA) respaldaron el plan de ajuste. La burguesía industrial se dividió: mientras, con dudas, los capitales más débiles cuestionaron el plan (la dirección de la CGE), los industriales de mayor tamaño (exdirigentes de la UIA, incorporados a la CGE) lo respaldaron.

A pesar del importante respaldo de la clase dominante al plan Rodrigo, su gestión terminó en un fracaso. Tras 45 días desde la puesta en marcha del plan, el ministro se vio forzado a renunciar, en medio de una crisis política desatada por la ofensiva del movimiento obrero contra el plan de ajuste. La forma en que se abortó el cambio en los lineamientos económicos, mediante la imposición de un límite al Gobierno por parte del movimiento obrero organizado, encendió luces de alarma. Esa alarma se notó claramente en los primeros balances de la crisis que hicieron distintas fracciones de la burguesía y terminó con el alejamiento 
de Celestino Rodrigo. La evaluación de la SRA, plasmada en un extenso documento difundido por la prensa, resulta representativa de lo que muchos sectores de la burguesía sostenían. Allí admitían los efectos recesivos y el "esfuerzo económico" que implicaba el "cambio de rumbo" para los asalariados, pero sostenían que los problemas serían menos graves si la crisis se enfrentaba con "realismo":

El pueblo tiene que pagar ahora errores que se cometieron anteriormente en la conducción de la economía nacional, donde con palabras altaneras se desfiguró la realidad y se pretendió violar principios económicos elementales, sacrificando la Argentina a fantasías ideológicas que fracasaron en todos los países que se sometieron a ellas (La Nación, 16/7/1975).

Durante los años previos, señalaron, se perdió una oportunidad de mejorar la situación del país por medio del incentivo a las exportaciones agropecuarias, a pesar de las advertencias de las entidades del sector. El Gobierno habría desoído estas advertencias influenciado por la "izquierda marxista":

La oportunidad se ha desperdiciado en forma irresponsable, a pesar de nuestras advertencias y quizás porque quienes advertimos a las autoridades éramos nosotros y no la extrema izquierda marxista que, con sus aliados ideológicos, aplaudía esa política que llevó al país al desastre (La Nación, 16/7/1975).

El balance era claro: el plan Rodrigo implicaba un ajuste duro pero necesario. Fueron los errores de las gestiones económicas anteriores los que habían llevado la situación a ese punto, y la única forma de salir era mantener el rumbo elegido o, incluso, profundizarlo. La declaración no era sólo un respaldo al plan, fuertemente cuestionado, sino una advertencia: no se podía volver atrás, la reedición del reformismo era insostenible.

\section{La Destitución de Celestino Rodrigo y la Radicalización Burguesa}

La salida de Rodrigo constituyó un punto de inflexión. Desde este momento, la burguesía se lanzó a una acción con un objetivo cada vez más claro: derrocar al Gobierno. La ofensiva se observó, por un lado, en la radicalización de los discursos. Comenzaron a reiterarse con insistencia una serie de elementos: en primer lugar, la caracterización de la situación como una crisis general, económica, política y social, producto 
de los errores del Gobierno. A su vez, aumentaron las referencias al problema de la "subversión", en la que englobaban ya no solo a las organizaciones armadas, sino también al activismo obrero que actuaba bajo la dirección de la izquierda: la "guerrilla fabril". Por último, se insistió una y otra vez en la incapacidad del Gobierno para dar salida a la crisis, acompañado de un permanente llamado al "restablecimiento del orden", con claras connotaciones golpistas.

Jorge Aguado, dirigente de la Carbap y activo impulsor de los "paros agrarios", se destacaba como el principal vocero de estas posiciones. Sus discursos, con amplia difusión en la prensa periódica, sintetizan estas ideas que comenzaban a plasmarse en los pronunciamientos de todas las corporaciones empresariales. El discurso pronunciado en un acto el 24 de julio de 1975 es un ejemplo de ello. Allí se refirió negativamente a la situación nacional y se responsabilizó por ella al Gobierno, al que atacaba con una virulencia inédita. Aseveró que la Nación se encontraba ante "una crisis general", que comprometía la existencia misma del poder del Estado, la posibilidad de una convivencia civilizada entre los argentinos y la estabilidad de las instituciones. Señaló que se vivían horas inciertas y difíciles para el país, ya que "fuerzas extrañas a nuestro ser nacional, no tan ocultas, pero de inconfesables designios, están listas para alzarse con el botín de la República a poco que la ciudadanía no se defienda". La alusión al fantasma de la "subversión" era clara. A continuación realizó un llamamiento a enfrentar la amenaza, luchando por devolver al país "tres factores fundamentales": autoridad, seguridad y confianza (La Nación, 25/7/1975). Un discurso decididamente golpista, que presentaba una crisis de magnitudes históricas a la que el Gobierno no podía ofrecer ningún tipo de salida. Y con una invocación final al restablecimiento de la "autoridad" que era un guiño apenas velado a una nueva intervención de las Fuerzas Armadas en la política argentina.

La CGE, impulsora de la política reformista que ahora aparecía en la picota, comenzó a experimentar una crisis interna producto del avance de las posiciones reaccionarias en la clase dominante. Ya a fines de 1974, la dirección nacional de la entidad debió soportar los cuestionamientos de algunas federaciones provinciales por su respaldo a las políticas reformistas en el agro (La Nación, 19/10/1974; Cronista Comercial, 19 y 21/10/1974). Cuando, tras la salida de Rodrigo, el Gobierno volvió a convocar a la CGE para reeditar el "Pacto Social", los cuestionamientos se intensificaron. 
Las federaciones provinciales de Salta y Tucumán objetaron, en agosto de 1975, que se siguiera insistiendo con programas económicos que habían fracasado. Las industrias alimenticias y los sectores agrarios que integraban la CGE, en medio de una crisis que afectaba particularmente a este sector, comenzaron a alejarse de la entidad. En abril de 1975, se desafiliaron varias empresas que dieron forma a la Coordinadora de las Industrias de Productos Alimenticios (Copal). En septiembre de 1975, dos entidades vinculadas con la actividad agropecuaria se escindieron de la CGE: la Bolsa de Cereales de Buenos Aires y la Unión General de Tamberos (La Nación, 8/9/1975). A comienzos de noviembre, se desvinculó también la Federación de Productores Frutícolas de Río Negro (Cronista Comercial, 1/11/1975).

De esta forma, la CGE perdía a las últimas corporaciones de la burguesía agraria que permanecían bajo su égida. La más importante de ellas, la FAA, se había desafiliado a mediados de julio de 1975. Su alejamiento fue el resultado de un largo proceso de enfrentamiento con el Gobierno nacional a raíz de los montos de renta capturados por el Estado, que la había llevado a confluir con las CRA y la SRA en los paros agrarios de ese año.

El viraje de la FAA, que se alejaba del reformismo para confluir en la alianza golpista, tuvo un correlato en sus declaraciones públicas, que fueron tomando distancia de los planteos de 1972 y 1973, cuando defendían la política reformista. A principios de julio, por ejemplo, coincidieron con el diagnóstico de Celestino Rodrigo y su crítica al núcleo de las políticas "populistas". Compartían la apreciación sobre el excesivo incremento del gasto público, en particular la crítica a la incorporación de nuevos agentes para mantener el nivel de empleo, en lugar de apuntar a mejorar la eficiencia de los servicios y aumentar su productividad. Se despacharon también contra la política de nacionalizaciones, a las que calificaban de "despilfarros" (La Tierra, 1/7/1975). También criticaron la política de promoción industrial, propiciada por las gestiones económicas reformistas. La superposición de desgravaciones, exenciones impositivas y préstamos oficiales a tasas muy bajas generarían una capa/un grupo de "empresarios parásitos", que no invertirían y se transformarían en "administradores de dinero ajeno" ( $\mathrm{La}$ Tierra, 24/7/1975). Acordes a la crítica de los empresarios golpistas, atacaron la política laboral del Gobierno, y llamaron a "reconsiderar" las condiciones pactadas en las convenciones colectivas de trabajo y a disciplinar a los gremios. Se hacían eco de los pedidos para enfrentar a 
la "guerrilla fabril", que impedía aumentar la productividad del trabajo (La Tierra, 28/8/1975 y 15/1/1976) ${ }^{7}$.

El giro no fue solo discursivo: luego del impasse de la gestión Rodrigo, la FAA, en alianza con las CRA y la SRA, se lanzó nuevamente a las calles para impugnar la política económica del Gobierno. Estas corporaciones volvieron a la carga con nuevos paros agrarios de alcance nacional. Sin embargo, ya no se trataba de paros demostrativos. Por su extensión, las nuevas medidas de protesta tuvieron un efecto desestabilizador sobre un Gobierno golpeado por la crisis. A fines de agosto, el frente conformado por las CRA y la FAA convocó un paro comercial ganadero de once días, al que se sumó la SRA, que se realizaría entre el 19 y el 29 de septiembre. Durante los días de paro prácticamente no se remitió hacienda a los mercados. También se afectó la comercialización de leche, por la adhesión de este sector de la producción.

A su vez, los productores agropecuarios se movilizaron a bordo de sus maquinas y realizaron cortes de ruta para visibilizar la protesta. Durante algunas jornadas, las industrias y comercios de varios pueblos del interior cerraron sus puertas en solidaridad con la protesta ganadera (La Nación, 26/9/1975; Cronista Comercial, 23, 25 y 26/9/1975; La Tierra, 25/9/1975; 2 y 16/10/1975). A poco de finalizada la medida, sus organizadores convocaron un nuevo paro para el 24 de octubre, que tendría una duración de 18 días. El anuncio repentino de la medida y su extensión tomó por sorpresa al Gobierno, que no pudo acumular stocks de hacienda. El masivo acatamiento tuvo entonces importantes consecuencias: su resultado fue un pronunciado desabastecimiento y el aumento en los precios de la carne y sus substitutos, que en un contexto inflacionario trajo graves problemas para el Gobierno (La Nación, $31 / 10 / 1975,1$ y 5/11/1975). A esto se sumaban los ya tradicionales cortes de ruta y las movilizaciones con maquinaria agrícola (La Nación, 30 y 31/10/1975; La Tierra, 6 y 13/11/1975). Los movilizados apelaron también a la intimidación y a la violencia para impedir que algunos productores remitieran su hacienda a los mercados. Ello derivó en algunos enfrentamientos con las fuerzas del orden, que produjeron detenciones (La Tierra, 30/10/1975).

En medio del paro, el presidente de la Carbap, Jorge Aguado, pronunció un discurso en la Bolsa de Cereales de Buenos Aires, donde defendió las medidas tomadas por los productores agropecuarios. Allí explicó que no se trataba sólo de una defensa de intereses sectoriales, ya 


\section{Gonzalo Sanz Cerbino}

que lo que estaba en juego era la "destrucción de la nacionalidad y del ser argentino", puesto en riesgo por la incapacidad del Gobierno (Aguado, 1977:209-210). También sostuvo que estaba surgiendo "el verdadero espíritu nacional que permitirá eliminar las antinomias entre argentinos".

Ese "espíritu" enfrentaría a las "filosofías políticas y económicas extrañas [...] que prometen la felicidad sin trabajo y a costa de los demás". "La hora de la verdad es inexorable", dijo al cerrar, mientras hacía pública su esperanza en un cambio de régimen frente a la debacle peronista (Aguado, 1977:211). Como dejó entrever en declaraciones periodísticas, se estaba librando una batalla entre las fuerzas del orden y la subversión. El Gobierno, que por acción u omisión favorecía a estos últimos, era un obstáculo que se debía remover. Por eso, las acciones de protesta, emprendidas para desestabilizar al Gobierno, servirían para torcer la balanza a favor de la restauración del orden:

No hay forma de solucionar los problemas sectoriales si no hay solución a los problemas generales del país [...] La acción cívica excede el marco de los intereses sectoriales para abarcar el conjunto de los intereses del país. [...] Espero que no sigamos dejando el camino libre a los activos enemigos de la nacionalidad y que recuperemos el poder de iniciativa tan necesario para desarrollar a la Nación con autoridad, seguridad, confianza y orden por lógica consecuencia. Pero que sea el orden de la civilización en libertad y no el que pretenden imponer las ideas comunizantes. Creo que ésta es la cuestión. Ojalá que los argentinos actuemos como hombres, si no queremos terminar siendo nada. (Aguado, 1977:229-230).

Similares apreciaciones se observan en los discursos de Celedonio Pereda, presidente de la SRA:

Debemos restaurar el orden y la autoridad necesarios para la convivencia. Debemos asumir plenamente el hecho de que se está librando una guerra decisiva y de que no somos ni podemos ser ajenos a ella, y que esa guerra se libra en muchos frentes, unos visibles, que son regados por la sangre de nuestras heroicas Fuerzas Armadas, otros disimulados y más peligrosos aún, como la infiltración en las fábricas, en las escuelas, en las universidades, como así también en la Administración Nacional. [Es necesario] luchar en todos los frentes. Debemos apoyar la acción gremial de todas las entidades representativas de cualquier sector sano del empresariado nacional que se identifiquen con nosotros en sus 
ideologías [...] Con esta intención es que integramos la Asamblea Empresaria (La Nación, 13/12/1975).

Pereda hacía referencia a la Asamblea Permanente de Entidades Gremiales Empresarias (Apege), constituida por varias corporaciones empresariales a las pocas semanas de la renuncia de Celestino Rodrigo, en agosto de 1975. Esta organización, integrada entre otros por la SRA, las CRA, la Carbap y Copal, junto a la Unión Comercial Argentina (UCA), la Cámara Argentina de Comercio (CAC), la Cámara Argentina de la Construcción (Camarco), la Cámara de Sociedades Anónimas (Camsocanon), la Asociación de Bancos Argentinos (Adeba) y la Bolsa de Comercio, fue la punta de lanza de los empresarios que ya habían comenzado a impulsar decididamente el golpe de Estado.

En septiembre de 1975, las entidades adheridas (de orden nacional, provincial o regional), llegaban casi a un centenar. Las cámaras que la integraban le otorgaron a la Apege, según el periódico La Nación, la representatividad de casi la totalidad del comercio y el sector agropecuario, aunque no se habían sumado todavía muchos industriales, que continuaban bajo la órbita de la CGE (La Nación, 19/9/1975). El capital comercial estaba representado por la UCA (comercio minorista) y CAC, que nucleaban a los importadores y a los grandes grupos económicos que hacían pie en el comercio, la industria y las finanzas (Bunge y Born, Astra, Techint, Braun, Garavoglio y Zorraquin, Roberts, Shaw, Acindar, Mihanovich y Celulosa, entre otros). La Adeba nucleaba a los bancos de capital nacional y la Camarco, a las grandes constructoras con intereses ligados a la obra pública. También se encontraba representada la gran burguesía terrateniente (SRA y CRA) y la agroindustria (Copal). La industria manufacturera urbana (CGE y UIA) todavía no se había plegado a esta alianza, aunque algunos de sus representantes se irían sumando a ella en los meses previos al golpe de marzo de 1976. En síntesis, podemos señalar que en el seno de la Apege actuaban algunos de los más encumbrados representantes de la burguesía local, que con sus aportes financiaban la actividad desplegada por el grupo (Itzcovitz, 1985 y 1987).

Desde un principio, la Apege cuestionó el manejo de la crisis por parte del Gobierno y fustigó el polo de los empresarios reformistas, nucleados en la CGE, a los que responsabilizaba de la situación imperante ( $\mathrm{La}$ Nación, 19/9/1975). Otro de los ejes de la intervención de la Apege fue el restablecimiento del orden, un llamado de claras connotaciones re- 
presivas en el que coincidían los núcleos golpistas (La Nación, 19/9/1975; Cronista Comercial, 1/11/1975). Un documento programático de la entidad, difundido a fines de octubre de 1975 señalaba que el país se encontraba frente a una "gravísima crisis", que no era sólo económica sino también ética, política y social: "La pérdida del principio de autoridad, la indisciplina, la inmoralidad, la incompetencia y la falta de seguridad para personas y bienes visibles son síntomas de un proceso de descomposición que urge remediar si deseamos sobrevivir como Nación" (La Nación, 23/10/1975). El intervencionismo estatal, la burocratización creciente y la subversión, que el Gobierno encubría, serían los causantes de esta situación. Sus alocuciones terminaban invariablemente pronunciándose por la "defensa de la empresa privada" y por "la restauración del orden y la seguridad" (La Nación, 14/12/1975).

Sin embargo, uno de los ejes principales de la intervención de la entidad fue el reclamo contra el "avance sindical", que afectaba "gravemente la economía nacional". En telegramas enviados a los ministros de Economía y Trabajo, solicitaron imperativamente que "se garantice el normal desenvolvimiento de las actividades laborales y se ponga fin a la inseguridad jurídica, económica y personal en que se ven obligadas a desenvolverse las empresas" (La Nación, 14/12/1975). En documentos posteriores, criticaron el avance de los sindicatos en "expresa contravención de las normas constitucionales", que ostentaban "privilegios irritantes" (La Nación, 14/12/1975; Cronista Comercial, 15/12/1975).

La crisis, en las alocuciones de la Apege, parecía reducirse a estos núcleos de activistas sindicales decididos a defender los derechos laborales adquiridos: "[...] la iniciativa y la empresa privada están sucumbiendo [...] la productividad desciende a niveles alarmantes y [...] la propiedad se encuentra amenazada; $[. .$.$] el país continúa su camino$ hacia el marxismo" (La Nación, 14/12/1975).

No podemos dejar de relacionar el énfasis puesto por estos núcleos empresariales en la activación sindical - que se presentaba como el principal problema económico y social del país - con el rol que tuvieron las comisiones internas de fábrica en la organización de la movilización y la protesta que derrotó el plan de ajuste de Rodrigo. Un dirigente político opositor, Ricardo Balbín, de la Unión Cívica Radical, bautizó el fenómeno como "guerrilla fabril". Una metáfora clara de cómo los secto- 
res empresariales percibían el problema, y de los métodos que demandaban para solucionarlo: así como las Fuerzas Armadas se estaban ocupando mediante el accionar represivo de la guerrilla urbana y rural, era menester aplicar los mismos métodos con la "guerrilla fabril".

Apuntaban claramente a la eliminación de los delegados sindicales combativos, cosa que no podía hacerse mientras siguieran vigentes las garantías democráticas. Para eso, hacía falta un golpe de Estado. Las Fuerzas Armadas, una vez derrocado el Gobierno, complacieron el reclamo empresarial: el mismo día del golpe, se militarizaron las principales zonas industriales del país. "Grupos de tareas" militares se hicieron presentes en las fábricas de mayor actividad sindical (entre otras, en las plantas de Ford, Acindar y Dálmine Siderca - del grupo Techint -, cuyos directivos integraban la Apege y el CEA), con listas que incluían los nombres de los principales activistas, que, según se constató mucho después, los propios empresarios confeccionaron.

Esos activistas fueron detenidos, llevados a prisiones clandestinas, torturados y asesinados. Muchos de ellos no volvieron a aparecer, y se convirtieron en "desaparecidos" (Basualdo, 2006). Así, con el golpe y el plan represivo instrumentado por las Fuerzas Armadas, los empresarios consiguieron disciplinar a estos activistas sindicales, lo que permitió instrumentar los programas económicos altamente impopulares que no pudieron implementarse en democracia.

\section{Los Vínculos Secretos}

Por su carácter secreto resulta difícil reconstruir las relaciones entre estos núcleos empresariales con la cúpula de las Fuerzas Armadas. Sin embargo, algunos elementos han trascendido. La SRA, por ejemplo, mantuvo una reunión con el Comandante en Jefe del Ejército, Jorge Rafael Videla, futuro presidente de facto de la Argentina, en noviembre de 1975. Allí, los ruralistas manifestaron, en un documento que se haría público después del golpe, su preocupación por el avance de la "subversión" en el ámbito agropecuario, a la que no se dudó en relacionar con la política del Gobierno:

La baja rentabilidad al productor [...] constituye un excelente caldo de cultivo para el desarrollo de concepciones extremistas; existen constancias de penetración subversiva a nivel de los productores medianos 
y pequeños, a través de entidades que constituyen ramas políticas del extremismo colectivista (MBSRA, 1975-1976).

El enemigo mayor, la "subversión", si no brotaba del propio Gobierno, por lo menos no era enfrentado decididamente desde allí:

La falta de seguridad física y jurídica ha determinado un clima de desconfianza. No se percibe una acción definida en contra del extremismo, [hay] desgobierno [y] un clima de terror creado por la guerrilla, a la que es difícil combatir por estar amparada en diversos niveles políticos y administrativos (MBSRA, 1975-1976).

La demanda que se desprende de este balance es clara: los militares debían alzarse con el poder para derrotar el "extremismo".

Jorge Aguado, activo organizador de los paros agropecuarios y, según indicaba la prensa, ideólogo de la Apege (Cronista Comercial, 7/8/1975), también contaba con aceitados vínculos con las Fuerzas Armadas, en particular con la facción que ocupó la gobernación de Buenos Aires bajo la dictadura, encabezada por el General Ibérico Saint Jean. Aguado integraba, junto a los juristas Jaime Smart y Alberto Rodríguez Varela (que había actuado también como/que también se había desempeñado como/que había sido también Consejero de la CAC), el círculo íntimo del gobernador. A ellos se les adjudicó la redacción del documento Un nuevo ciclo histórico argentino: del Proceso de Reorganización Nacional a la Tercera República, con el que Saint Jean intervino en la discusión sobre los objetivos políticos de la dictadura.

Allí se planteaba como norte la instauración de una democracia restringida, que limitara al mínimo la participación de la ciudadanía y relegara a los partidos políticos existentes de la futura transición. El grupo capitaneado por Saint Jean se postulaba como recambio de la facción comandada por el presidente Videla, a quien cuestionaba por su excesivo "politicismo" y por la "tibieza" en el accionar represivo. No por nada se ubicaba a Saint Jean entre los "duros", que demandaban extender y profundizar la represión. Para esa tarea, el gobernador bonaerense había montado una estructura represiva propia, paralela a la de las Fuerzas Armadas, comandada por el Jefe de la Policía Bonaerense, Ramón Camps, de la que dependían 29 centros clandestinos de detención. A Aguado se le adjudicó también injerencia en la estructuración del poder municipal en la provincia, en donde colocó a civiles y militares de su confianza. Las cuotas de poder acaparadas por 
Jorge Aguado le permitieron ubicar a cuadros de su confianza provenientes de la Carbap en distintas funciones. Así, Jorge Girado, segundo exvicepresidente de esa entidad, actuó/se desempeñó como Ministro de Asuntos Agrarios de la Provincia de Buenos Aires desde 1976, y Raúl Salabarren, posteriormente, fue ministro de Economía provincial. Con la salida de Videla y la llegada de Viola a la presidencia, Aguado ocupó la cartera de Agricultura y Ganadería de la Nación. Posteriormente, fue ungido gobernador de la Provincia de Buenos Aires, bajo la presidencia del General Galtieri. Allí, se hizo acompañar nuevamente por dirigentes de la Carbap, como Héctor Orbea, subsecretario de Asuntos Agrarios. A su vez, Salabarren pasó a ocupar la Secretaría de Agricultura y Ganadería de la Nación, mientras que otro dirigente de CARBAP, Ignacio García Cuerva, ocupó la subsecretaría de Agricultura nacional (Palomino, 1989: 117; Canelo, 2008; Palermo y Novaro, 2003: 169-260; Muleiro, 2011).

Sin embargo, el núcleo empresarial de mayor influencia sobre los círculos militares parece haber sido el CEA. Tanto su presidente, José Alfredo Martínez de Hoz, como su director ejecutivo, Enrique Loncan (consejero de la CAC y dirigente de la Adeba por su participación en el Banco de Quilmes), fueron activos animadores de las reuniones secretas en las que se fijaron los lineamientos del plan económico dictatorial. Importantes dirigentes empresariales, muchos de los cuales llegaron a ser funcionarios de la dictadura, participaron asiduamente de reuniones y tertulias (organizadas, entre otros, por el Club Azcuénaga, la Peña El Ombú y el Círculo del Plata) en los meses previos al golpe, a las que asistían también algunos de los generales que se hicieron con el poder en 1976. Entre los asiduos concurrentes a estas reuniones podemos contar a Mario Cadenas Madariaga, dirigente de las CRA y futuro funcionario dictatorial, Alberto Rodríguez Varela, consejero de la CAC y futuro ministro de la dictadura, Horacio García Belsunce, directivo de Acindar y dirigente de la CAC, y Armando Braun, presidente de la CAC y miembro del secretariado ejecutivo de la Apege. Este no era el único dirigente de la Apege vinculado al CEA: César Polledo, presidente de la Cámara de la Construcción, y Celedonio Pereda, presidente de la SRA, formaban parte de la dirección de ambas instituciones. También Eduardo García, representante del grupo Techint en la CAC-de la que/donde llegó a ser presidente -, era miembro del CEA. Estas no eran excepciones: los grandes grupos económicos que integraban el CEA participaban, a su vez, de la dirección de la CAC y, por extensión, de la Apege: Techint, Astra, Braun, Bunge y Born, Acindar, Noel, 
Soldati. A su vez, los grandes bancos que integraban el CEA, como el Galicia, eran parte de la dirigencia de la Adeba e integraban, por lo tanto, la Apege. (Muleiro, 2011:55-95; Itzcovitz, 1985 y 1987).

Tras el golpe, muchos de estos dirigentes fueron ungidos funcionarios. Martínez de Hoz fue ministro de Economía entre 1976 y 1981, y lo acompañaron en su gestión Mario Cadenas Madariaga, en la Secretaría de Agricultura y Ganadería, y Juan Alemann - que venía de dirigir el Instituto de Investigaciones Económicas de la SRA - como secretario de Hacienda. Su hermano, Roberto Alemann, Consejero de la CAC, fue ministro de Economía entre 1981 y 1982. Alberto Rodríguez Varela, Consejero de la CAC ligado a Jorge Aguado y la Carbap, ocupó el cargo de ministro de Justicia en 1978 y el de rector de la Universidad de Buenos Aires en 1982. Estos son apenas dos ejemplos del rol de la CAC como proveedora de funcionarios de la dictadura militar: 16 consejeros de esta entidad ocuparon cargos en el gobierno militar entre $1976 \mathrm{y}$ 1983. La lista abarca desde subsecretarios y secretarios de Estado hasta embajadores, incluyendo también jueces de la Suprema Corte, directores de empresas y bancos públicos. A su vez, dos importantes dirigentes de la Sociedad Rural, las CRA y la Apege acompañaron a Cadenas Madariaga en su gestión al frente del Ministerio de Agricultura: Alberto Ramón Mihura como subsecretario de Ganadería y Jorge Zorreguieta como subsecretario de Agricultura. Tras la salida de Cadenas Madariaga, Zorreguieta ocupó el puesto vacante, que desempeñó entre 1979 y 1981 (Muleiro, 2011:55-95; Palomino, 1988: 132). Eduardo Oxenford, titular del Banco Francés que integraba la dirección de la Adeba (y Apege), fue director de la petrolera estatal YPF, entre 1978 y 1979, y ministro de Industria y Minería en 1981. Francisco Soldati, titular de la Compañía Comercial del Plata y socio del Banco de Crédito, integrante del CEA y la Adeba, fue director del Banco Central de la República Argentina en 1976. Estos son solo dos de los diez dirigentes de la Adeba que ocuparon cargos jerárquicos en la administración pública entre 1976 y 1983.

Esto parece indicar la existencia de una división de tareas dentro de los núcleos empresariales: a través del CEA se canalizaban las relaciones con las Fuerzas Armadas; mientras que la Apege, y las corporaciones que la integraban, eran el instrumento que estos mismos dirigentes empresariales utilizaban para organizar, en pos de sus objetivos, a los empresarios que no tenían acceso directo a las esferas de poder. 


\section{LA OFENSIVA FINAL}

A fines de 1975, el clima estaba decididamente inclinado hacia la salida golpista: amplios sectores del empresariado estaban convencidos de que esa era la única solución a una crisis que rebasaba por mucho lo económico y actuaban decididamente a favor del quiebre de la legalidad democrática. Sin embargo, faltaba resolver dos problemas: 1) Algunos empresarios, en particular los que se nucleaban en la CGE, todavía respaldaban al gobierno democrático. 2) No estaba clara la reacción que podían tener la clase obrera y los sectores medios frente al golpe. Si estos sectores no veían el golpe como la única alternativa frente al caos, los militares podían encontrar resistencias que hicieran peligrar sus planes. Para torcer la balanza en su favor, los golpistas iniciaron una última embestida contra el régimen democrático en diciembre de 1975, encabezada por Apege/ una última embestida contra el régimen democrático - encabezada por la Apege - en diciembre de 1975.

El intento gubernamental de sancionar una nueva reforma impositiva fue la excusa que permitió unificar al conjunto de la burguesía en esta empresa. Entre diciembre y enero, la Apege publicó solicitadas en la prensa y convocó a una serie de asambleas, en donde se exigió con vehemencia un ajuste económico y un disciplinamiento de los trabajadores que el Gobierno, muy debilitado, no estaba en condiciones de realizar (La Nación, 20/12/1975 y 27/1/1976). El Cronista Comercial, un periódico de tirada nacional, caracterizaba/señalaba que el objetivo de la embestida no era ya modificar el plan económico, sino desplazar al propio Gobierno/caracterizaba el objetivo de la embestida como el desplazamiento del propio Gobierno y ya no la modificación del plan económico: "Los sectores económicos adversos a la política de concertación, nucleados en la Apege, han lanzado en los últimos días una enérgica ofensiva cuyo destinatario, más que la conducción económica, es el Gobierno en su conjunto" (Cronista Comercial, 15/12/1975). Para forzar la situación, la Apege convocó a una medida de fuerza para el 16 de febrero: un lock out general. Ese día se paralizaría, en todo el país, la actividad productiva.

Durante las dos primeras semanas de febrero, fueron llegando adhesiones de distintas cámaras al lock out, votadas en centenares de asambleas de empresarios en todo el país. Muchas de estas cámaras estaban adheridas a la CGE, pero no obedecieron la posición oficial de su dirección de no respaldar la medida (La Nación, 16/2/1976). La central 
reformista fue desmembrándose ante la ofensiva final de la Apege, convirtiéndose en una cáscara vacía en la antesala del golpe/Ante la ofensiva final de la Apege, la central reformista fue desmembrándose y convirtiéndose en una cáscara vacía en la antesala del golpe. Según los organizadores, las cámaras que adhirieron al "paro empresarial" llegaron finalmente a 1.200 (La Nación, 14/2/1976). La adhesión osciló entre el 80 y el $90 \%$ de las empresas de todo el país y las crónicas periodísticas hablan de un acatamiento mayoritario (La Nación, 16 y 17/2/1976). A diferencia de los últimos paros agrarios de 1975, el lock out de la Apege no tuvo efectos materiales significativos. Los paros agrarios, por su duración, generaron problemas de abastecimiento y el aumento en los precios de la carne, en un contexto económico ya signado por la hiperinflación y el desabastecimiento. No fue el caso del lock out del 16 de febrero de 1976. Sin embargo, el impacto político de la medida fue aún más importante. El apoyo masivo de la burguesía al "paro empresarial", y por ende, al programa golpista impulsado por la Apege, quedó cabalmente demostrado. El Gobierno democrático había perdido el apoyo de la clase dominante, lo que se constataba especialmente en la crisis que la convocatoria ocasionó en la CGE. A su vez, la medida sirvió también para medir el respaldo que aún conservaba el Gobierno en la clase obrera. La completa pasividad de los trabajadores, que no salieron a enfrentar el paro golpista ni a defender el régimen, terminó de definir su suerte. El futuro golpe de Estado tenía el respaldo de la clase dominante, y se había obtenido, por lo menos, la neutralidad del resto de los sectores.

A lo largo de esta reconstrucción, hemos podido ver cómo se organizó la alianza que impulsó el golpe de Estado de 1976 en la Argentina. Las Fuerzas Armadas no actuaron con autonomía y en abstracción de otros intereses sociales, como postulan ciertas interpretaciones (Conadep, 1984:7-12). Por el contrario, observamos que han sido el instrumento de un sector mayoritario de la clase dominante, que visualizaba en el quiebre de la legalidad democrática y en el plan represivo instrumentado la única salida a una crisis general del orden capitalista. La derrota del plan de ajuste impulsado por Rodrigo, por la acción obrera dirigida por elementos de la izquierda revolucionaria, encendió el alerta. La clase dominante pareció comprender, como muestran las acciones que emprendió de allí en adelante, que la resolución de la crisis solo podría realizarse si se daba antes un paso previo: disciplinar a la clase obrera, derrotando y eliminando a sus sectores más movilizados. 
Esto no podía hacerse dentro de los marcos democráticos, y por esa razón el golpe militar se transformó en la única alternativa viable. La ofensiva desatada en la segunda mitad del año buscaba diferentes objetivos. El primero, generar el máximo desgaste posible al Gobierno de Isabel Perón, arrebatándole el poco respaldo que le quedaba. Luego, nuclear tras el programa golpista al conjunto de las fracciones de la clase dominante, para lo que se emprendió un ataque sistemático contra la corporación empresarial, la CGE, que reunía a aquellas fracciones afines al Gobierno. Y por último, neutralizar a los sectores de la clase obrera que podrían enfrentar el golpe, presentando esta opción como única alternativa posible frente al caos y la anarquía. Un rol cabal en la gestación del golpe correspondió a dos organizaciones: el CEA y la Apege. Esta última, a través de su acción pública, cumplió el rol de organizar al empresariado y ponerlo en pie de guerra contra el Gobierno. Tuvo también una tarea propagandística, al difundir las ideas reaccionarias que se materializarían con el golpe. La acción del CEA, por el contrario, tuvo un carácter secreto: allí se delineó el programa económico de la dictadura y se trazaron los vínculos con los altos oficiales de las Fuerzas Armadas que encabezarían la acción política. De esta forma, paso a paso, estos núcleos empresariales fueron generando las condiciones para conseguir sus objetivos: el quiebre de la legalidad democrática que permitiera generar las condiciones represivas para disciplinar a los sectores movilizados del movimiento obrero, para, de esa manera, poder implementar sin oposición el programa de ajuste económico que necesitaban para restablecer la acumulación de capital.

(Recebido para publicação em agosto de 2014)

(Reapresentado em março de 2015)

(Aprovado para publicação em maio de 2015)

DADOS - Revista de Ciências Sociais, Rio de Janeiro, vol. 59, no 1, 2016 


\section{Gonzalo Sanz Cerbino}

\section{NOTAS}

1. Hemos desarrollado el punto en Baudino y Sanz Cerbino (2013a).

2. Hemos desarrollado este tema en Baudino y Sanz Cerbino (2013b).

3. Sobre el avance del sector de Aguado en las corporaciones rurales, ver Memoria y Balance de CARBAP (en adelante, MBCAR), 1973-1974, y Aguado (1977). Sobre la oposición anti-reformistra en la FAA, puede consultarse el periódico La Tierra (en adelante, LT) de las fechas 4/10/1973, 31/1/1974 y 13/6/1974. Sobre la crítica a la política de reformas, ver MBCAR 1973-1974; Memoria y Balance de SRA (en adelante, MBSRA), 1973-1974 y 1974-1975; y Aguado (1977: 23-135).

4. Hemos reconstruido los paros agrarios tomando información de fuentes periodísticas, en particular La Nación (LN), Cronista Comercial (CC) y LT (fechas varias).

5. Ver, por ejemplo, La Nación, 9 y 13/6/1975; Cronista Comercial, 14/6/1975 y Anales de la Sociedad Rural Argentina (ASRA), año CIX, no 1 y 2, enero-febrero de 1975.

6. LT, 12/6/1975; CC, 14/6/1975 y 5/7/1975; LN, 5, 12 y 14/6/1975.

7. Este giro a la derecha en el discurso de la FAA fue observado también por otros autores: ver, por ejemplo, Poggi (2012). 


\section{BIBLIOGRAFÍA}

AGUADO, Jorge. (1977), Cuatro Años de Acción Gremial. Buenos Aires, Carbap.

ÁGUILA, Gabriela. (2008), “La Dictadura Militar Argentina: Interpretaciones, Problemas, Debates". Páginas, año 1, no 1, pp. 9-27.

ASPIAZU, Daniel; BASUALDO, Eduardo; KHAVISSE, Miguel. (2003), El Nuevo Poder Económico en la Argentina de los Años 80. Buenos Aires, Siglo XXI.

BALVÉ, Beba; BALVÉ, Beatriz. (2005), El '69. Huelga Política de Masas. Buenos Aires, Ediciones Ryr.

BASUALDO, Victoria. (2006), “Complicidad Patronal-militar en la Última Dictadura Argentina. Los Casos de Acindar, Astarsa, Dálmine Siderca, Ford, Ledesma y Mercedes Benz". Engranajes, no 5, pp. 1-21.

BAUDINO, Verónica. (2012), La Estrategia de la Unión Industrial Argentina 1966-1976. Tesis (Doctorado en Historia), Universidad de Buenos Aires, Buenos Aires.

BAUDINO, Verónica; SANZ CERBINO, Gonzalo. (2013a), “Corporaciones Empresarias, Alianzas Sociales y Disputas Políticas en el Retorno del Peronismo (1969-1974)". Trabajo y Sociedad, vol. XVII, no 22, pp. 395-416.

(2013b), "El Tercer Gobierno de Perón y la Fractura de la Clase Dominante". Estudios del ISHIR, vol. 3, no 6, pp. 84-110.

CANELO, Paula. (2008), El Proceso en su Laberinto. La Interna Militar de Videla a Bignone. Buenos Aires, Prometeo.

CASTELlANI, Ana. (2010), Estado, Empresas y Empresarios. La Construcción de Ámbitos Privilegiados de Acumulación entre 1966 y 1989. Buenos Aires, Prometeo.

CONADEP (Comisión Nacional sobre la Desaparición de Personas). (1984), Nunca Más. Buenos Aires, Eudeba.

FERRERES, Orlando. (2007), Dos Siglos de Economía Argentina. Historia Argentina en Cifras. Buenos Aires, Norte y Sur.

IÑIGO CARRERA, Juan. (2007), La Formación Económica de la Sociedad Argentina. Buenos Aires, Imago Mundi.

ITZCOVITZ, Victoria. (1985), Organizaciones Corporativas del Empresariado Argentino: La Cámara Argentina de Comercio. Buenos Aires, CISEA.

(1987), Organizaciones de los Empresarios. Un Análisis de su Representatividad, Dirección y Comportamiento. Comunicación presentada en el seminario "Hacia una etnografía de las organizaciones". Buenos Aires, 3 al 6 de noviembre.

IZAGUIRRE, Inés. (1998), "La Memoria de la Política y la Política de la Memoria en la Argentina". Razón y Revolución, no 4, pp. 69-79.

et al. (2009), Lucha de Clases, Guerra Civil y Genocidio en la Argentina. 1973-1983. Buenos Aires, Eudeba.

KANDEL, Pablo; MONTEVERDE, Mario. (1976), Entorno y Caída. Buenos Aires, Planeta.

LÖBBE, Héctor. (2009), La Guerrilla Fabril. Clase Obrera e Izquierda en la Coordinadora de Zona Norte del Gran Buenos Aires (1975-1976). Buenos Aires, Ediciones Ryr.

DADOS - Revista de Ciências Sociais, Rio de Janeiro, vol. 59, nº 1, 2016 


\section{Gonzalo Sanz Cerbino}

MULEIRO, Vicente. (2011), 1976. El Golpe Civil. Buenos Aires, Planeta.

O'DONNELL, Guillermo. (2008), Catacumbas. Buenos Aires, Prometeo.

(2009), El Estado Burocrático Autoritario. Buenos Aires, Prometeo.

PALERMO, Vicente; NOVARO, Marcos (2003), La Dictadura Militar (1976-1983). Del Golpe de Estado a la Restauración Democrática. Buenos Aires, Paidós.

PALOMINO, Mirta. (1988), Tradición y Poder: La Sociedad Rural Argentina (1955-1983). Buenos Aires, CISEA.

PALOMINO, Mirta (1989), Organizaciones corporativas del empresariado argentino. CARBAP (Confederación de Asociaciones Rurales de Buenos Aires y La Pampa) 1955-1983. Buenos Aires, CISEA.

POGGI, Marina. (2012), “El Desvanecimiento del Discurso Reformista. El Rol de la Prensa Argentina en la Cuestión Agraria durante 1975 y 1976". Global Media Journal México, vol. 9, no 18, pp. 1-15.

RAPOPORT, Mario. (2000), Historia Económica, Política y Social de la Argentina. Buenos Aires, Macchi.

; ZAIAT, Alfredo. (2013), “La Complicidad de las Cámaras Patronales Agropecuarias", en H. Verbitsky; J. Bohoslavsky (eds.), Cuentas Pendientes. Los Cómplices Económicos de la Dictadura. Buenos Aires, Siglo XXI, pp. 299-314.

RESTIVO, Néstor; DELLATORRE, Raúl. (2005), El Rodrigazo, 30 Años Después. Un Ajuste que Cambió al País. Buenos Aires, Capital Intelectual.

SCHVARZER, Jorge. (1987), La Política Económica de Martínez de Hoz. Buenos Aires, Hyspamérica.

. (1990), Estructura y Comportamiento de las Grandes Corporaciones Empresarias Argentinas (1955-1983). Un Estudio desde Dentro para Explorar su Relación con el Sistema Político. Buenos Aires, CISEA.

SIDICARO, Ricardo. (2002), Los Tres Peronismos. Estado y Poder Económico 1946-55/1973-76/1989-99. Buenos Aires, Siglo XXI.

VEZZETTI, Hugo. (2002), Pasado y Presente. Guerra, Dictadura y Sociedad en la Argentina. Buenos Aires, Siglo XXI.

\section{Fuentes y Documentos}

La Tierra (LT), periódico oficial de la FAA, fechas varias.

La Nación (LN), periódico de tirada nacional, fechas varias.

Cronista Comercial (CC), periódico de tirada nacional, fechas varias.

Anales de la Sociedad Rural Argentina (ASRA), fechas varias.

Memoria y Balance de CARBAP (MBCAR), fechas varias.

Memoria y Balance de SRA (MBSRA), fechas varias. 


\section{RESUMO}

A Participação Empresarial na Conspiração Golpista na Argentina (1975-1976)

O golpe de Estado consumado na Argentina em 1976 foi o resultado de uma extensa conspiração que envolveu importantes frações da burguesia local. Este artigo pretende discutir este problema, pouco analisado nas ciências sociais, reconstruindo a ofensiva golpista iniciada em 1975. Após analisar os posicionamentos públicos, as ações de protesto e os vínculos políticos de diversas agrupações e corporações empresariais com os militares, o texto demonstra que as Forças Armadas não atuaram por conta própria ao efetivar o golpe, sendo pelo contrário o instrumento de uma ampla aliança social conformada para tal fim.

Palavras-chave: conflito social; classe dominante; poder político; ditadura; corporações empresariais

\section{ABSTRACT \\ The Participation of the Business Elite in the Coup Conspiracy in Argentina (1975-1976)}

The State coup consumed in Argentina in 1976 was the result of an extensive conspiracy which involved significant fractions of the local bourgeoisie. This article intends to discuss this under-analyzed problem, reconstructing the coup offensive initiated in 1975. After analyzing the political positions, the actions of protests and the political ties of several groups and businesses corporations with the military, the text demonstrates that the Armed Forces did not operate alone in carrying out the coup - on the contrary, they were a tool used by a wide-ranging social alliance organized to this end.

Keywords: social conflict; dominant class; political power; dictatorship; business corporations 


\section{Gonzalo Sanz Cerbino}

\section{RÉSUMÉ}

La Participation du Monde de l'Entreprise au Coup d'État en Argentine (1975-1976)

Le coup d'État argentin de 1976 a été le résultat d'une conspiration de grande envergure impliquant des pans importants de la bourgeoisie locale. Cet article entend se pencher sur ce problème, encore peu analysé par les sciences sociales, dans le but de procéder à la reconstruction de l'offensive lancée en 1975 en vue du coup d'État. Après avoir analysé les prises de position publiques, les actions de protestation et les liens politiques avec les militaires de différents groupes liés au monde de l'entreprise, ce texte s'attachera à montrer que les Forces armées n'ont pas agi pour leur propre compte en mettant en œuvre le coup d'État, mais ont au contraire constitué l'instrument d'une large alliance sociale organisée à cette fin.

Mots-clés: conflit social; classe dominante; pouvoir politique; dictature; monde de l'entreprise

\section{RESUMEN}

La Participación Empresarial en la Conspiración Golpista en Argentina (1975-1976)

El golpe de Estado consumado en la Argentina en 1976 fue el resultado de una extensa conspiración que involucró a importantes fracciones de la burguesía local. Este artículo pretende echar luz sobre el problema, poco estudiado por las ciencias sociales, reconstruyendo la ofensiva golpista que se inicia en 1975. Tras analizar en detalle los posicionamientos públicos, las acciones de protesta y los vínculos políticos de distintos agrupamientos y corporaciones empresariales con los militares, el texto demuestra que las Fuerzas Armadas no actuaron por su cuenta al perpetrar el golpe, sino que fueron el instrumento de una amplia alianza social conformada para tal fin.

Palabras clave: conflicto social; clase dominante; poder político; dictadura; corporaciones empresarias 